\title{
Methodological aspects of the implementation of additional education in robotics
}

\author{
Oksana Kadeeva ${ }^{1, *}$, Alexander Belov ${ }^{1,2}$, Valentina Syritsyna $^{1}$, Svetlana Maksimenko ${ }^{1}$, and \\ Viktor Sinko ${ }^{1}$ \\ ${ }^{1}$ Far Eastern Federal University, 10 Ajax Bay, Russky Island, Vladivostok, 690922, Russian \\ Federation \\ ${ }^{2}$ Primorskaya State Academy of Agriculture, 44 Bluhera st., Ussuriisk, 692510, Russian Federation
}

\begin{abstract}
The purpose of the study is actualized by the fact that progress in the field of computer technology and robotics allows radically changing the idea of teaching computer science to schoolchildren, or rather programming in a modern secondary school, realizing one of the most important tasks facing the education system today. The scientific novelty of the study lies in the fact that these achievements allow updating traditional teaching methods, making them much more useful and modern. Nowadays, students have the opportunity to study various programming languages at school and at the same time, using the developed resources, observe the process of their execution by specially created robots, which can develop the student's desire to study further and give motivation to study the academic discipline. The practical significance of the work lies in the fact that one of such projects containing educational resources and allowing a different look at modern computer science lessons is LEGO and ROBBO. The advantages and disadvantages of traditional methods of teaching programming languages in high school are analyzed in the study. Also, the advantages of learning programming with LEGO and ROBBO are revealed, methodological recommendations for using the LEGO and ROBBO programming environment are presented, the capabilities of the LEGO project and ROBBO are described, and their main elements are characterized.
\end{abstract}

\section{Introduction}

The topic is relevant due to the fact that in the modern world, when information and communication technologies are actively and rapidly entering everyday life, the need to prepare schoolchildren in the field of computer science is of great importance. In this regard, such a subject as computer science occupies a special place in the system of modern education. However, in the modern high school, the study of the programming course takes place mainly at the introduction level, which is associated with the programmed control of the computer. Programming is one of the most important components of computer science and at the same time it causes the greatest difficulties for schoolchildren during the study.

\footnotetext{
* Corresponding author: opgamen@mail.ru
} 
The fact is that modern computer science textbooks, which include the section "Algorithmization and Programming" and are designed for the basic level, present educational material in such a form that excludes the participation of computer technology. Therefore, the purpose of this study is a methodological substantiation and presentation of the foundations of additional education in robotics based on the LEGO and ROBBO sets. To achieve this research goal, it is necessary to solve the following tasks: first, to reveal the methodological component of educational robotics in the framework of secondary school; secondly, to demonstrate the capabilities and principles of the LEGO and ROBBO constructors; third, to experimentally test the effectiveness of the introduction of educational robotics into the system of additional education for students [13-15].

\section{Methods}

Extracurricular activities as the main element of additional education are an environment for communication and joint activities, in which each student can test himself and his capabilities, as well as demonstrate them to others. Thus, this form of work is the most common and traditional. When studying the additional educational process in computer science, the following research methods were used: analysis of educational, methodological and scientific literature, algorithmization and programming, approbation and survey of students of $6^{\text {th }}-7^{\text {th }}$ classes.

At the same time, the theoretical basis of the study in the field of additional education and extracurricular activities is the work of S.G. Kosaretsky [4], E. A. Kuznetsova [5] and others revealing the need to use robotics in the educational process. In the field of influence of construction sets on the spatial thinking of students, the study of O.G. Dieva [2] plays an important role, and the material on programming languages and their influence on additional education in computer science $[1,6,11]$ is taken as a basis. The practical significance of the study lies in the fact that the use of various technical means, for example, a robotic construction set, in combination with visual programming, is capable of developing spatial thinking in children, which is also a huge advantage in teaching programming.

\section{Results and discussion}

Visual training should be diverse not only in the diversity of actions performed, but also have different types and means. That is why the project was developed and the ROBBO robotic platform was created [7]. The capabilities of this robotic platform make it possible to make the process of teaching programming much more interesting and, most importantly, more useful. Students will be able to independently program the robot to perform certain actions related to orientation in space. For example, a well-written program can make a robot move in a circle, avoid obstacles, stop in front of an object, or follow lines of a certain color. The use of robots in learning is also an interdisciplinary connection. This is not even just about such subjects as computer science, mathematics or physics, which will be discussed later, but this is an excellent opportunity to acquaint students with the history of the development of robotics in the world and in their home country. The student can find out when the first robots appeared and what they were used for, in what areas of human life it is necessary to use robots, what robotic developments are used in the country, what progress robotics has achieved today, and what we can expect in the future. It is also a great opportunity to allow students to find what would interest them and what they could share in the lesson, i.e. introduce them to the relevant literature. Students can give a variety of messages or designed presentations on topics of their choice that will reflect student 
interest in learning the subject. Thus, the use of ROBBO equipment will develop spatial thinking and the ability to navigate in space in schoolchildren much more effectively than traditional teaching methods. In addition, the use of ROBBO will contribute to interdisciplinary communication, which will lead to the consolidation of the knowledge already acquired by the student and the acquisition of new ones. ROBBO is a free project that is used to teach children how to operate robots and open source programming. An important task of this project is to teach children programming based on the knowledge gained about algorithms and how to create them. One of the features of ROBBO is its versatility. This means that its resources can be used in various school disciplines, i.e. not only in computer science lessons, but also in physics or mathematics lessons. Having received certain knowledge in the field of programming, the student will be able to apply this knowledge in a physics lesson, where they will be supplemented by knowledge in the field of mechanics and electrodynamics $[8,11]$. For example, a student, having written the correct program, will be able to calculate the path traveled by the robot, find its speed and time.

At the same time, another important feature of ROBBO is its creative orientation, since it is, in essence, a robotic constructor. The ability to study the structure and functionality of robots, create custom modules from existing parts and repair existing modules, all this has a clear goal of developing creative and even engineering abilities in a child. The child can decide for himself which modules to use, which commands the robot will execute, and how to supplement its functionality. For example, the learner can make the robot move when light hits the device, make the robot move along lines, or avoid obstacles. It all depends on what task the child sets for himself and what he can contribute to this process. Starting from a very young age, children begin to build various towers and pyramids from cubes and rings, make their own houses and fortresses from chairs and pillows, in another words, they show creativity. In turn, the modern world and the education system allow combining business with pleasure and at the same time getting the most positive result $[6,12]$. Thus, the robotics of the ROBBO project is able to supplement the material learned in the lessons of computer science, physics and mathematics, to develop the child's creative abilities, to give the opportunity to express themselves and give motivation for further learning.

The Danish company Lego is also a generally recognized leader among constructors. Today, the Lego company produces the following lines of constructors designed for different age groups: Pre School DUPLO, Learn to learn, Build your story (Story Starter), More To Math, We Do, Machines and mechanisms, Technology and physics, MINDSTORMS Education. Let us briefly consider some of them [3, 9].

Lego Pre School Duplo - designed for preschool children (from one year) and is aimed at developing the child's motor skills. There are a large number of Pre School Duplo kits distributed on various topics: public transport, a young programmer, a castle with knights and others. The complete set and the number of parts vary depending on the set. At the same time, due to the age category of children, the elements of the constructor here are much bigger than in other sets.

Lego Education We Do - designed for primary school children and allows creating simple mechanisms. Suitable for learning the basics of design robotics and allows achieving many educational goals (finding new solutions and analyzing results; establishing causeeffect relationships; developing experimental thinking; using tables to display data; building three-dimensional solutions from two-dimensional drawings; developing logical thinking). The set contains 158 elements: Lego parts, Lego USB Hub, motor, motion and tilt sensors. The Lego USB Hub is a USB switch that connects to your computer and allows controlling sensors and motors through the Lego Education We Do Software. The program can work with three switches at the same time. Besides the main set, there are additional 
elements on sale that allow implementing projects in physics, geography, biology, engineering design and space exploration.

Lego Education - Learn to learn - designed for primary school children. The set includes 28 sets, each set has 72 elements, as well as teaching materials. This complex allows students to better master the school curriculum. The educational-methodical complex of the Learn to learn set includes three initial and 15 additional lessons. Initial lessons are aimed at demonstrating to students and teachers the practical application of the set in the educational process. In turn, additional lessons are distributed across five primary school subject areas: mathematics, computer science, technology, language learning and literary reading.

Lego Education - Story Starter - designed to develop humanitarian and communication skills. With the set, students learn to create different stories using the constructor. The basic set of Lego Education - Story Starter includes: building materials for assembling 5 action scenes; figurines of animals, people, toy plants; various props: boxes, dishes, guns, interior elements; two sorting trays and picture cards to help you plot the story. Also, the Story Visualizer program is included in the set, which allows creating comics based on stories that students invented while interacting with the constructor. This program can be installed both on a computer and on a phone or tablet, which will allow students to improve their skills in handling this equipment.

Lego "Machines and mechanisms" - intended for children from 8 to 11 years old. The constructor allows students to assemble various technical means and, with their help, solve set tasks. Students learn mechanical principles such as screw, gear, lever, ratchet, cam, and others. The set is designed for 38 lessons with basic tasks, 4 lessons with basic tasks and 6 creative lessons.

Lego MINDSTORMS Education - designed for middle and high school students. This set is more complex than those presented above. With the help of this constructor, students can create complex mechanisms that use various motors, sensors, as well as a microcomputer. In addition to technical training, the constructor will allow children to learn the basics of object-oriented programming used to solve problems. The main component of the constructor is a microcomputer (microprocessor), which, in turn, is the "brain" of the robot. It allows the robot to "come to life" and guide it, performing the actions recorded by the creator. The microcomputer itself consists of: a processor, FLASH memory (16 megabytes), a Linux operating system and various necessary ports. The next important element is the servo motor, which communicates between the robot and the microcomputer, and allows it to move using the built-in rotation sensor. The Lego Mindstorms EV3 robot receives information about the world around it from several sensors: an ultrasonic sensor, a touch sensor and a sensor that allows for color recognition.

If we talk about the LEGO and ROBBO projects, then one lesson for using their resources will not be enough, and there is no need for this. LEGO and ROBBO resources can help you understand many of the commands and learn how to create algorithms that you can use during the lesson. However, it takes much longer to delve into these environments. To do this, it is necessary to organize special courses or clubs for both students and teachers who want to broaden their horizons and gain knowledge in order to use them later in practice. At the same time, it should be noted that practice shows the ease of assimilation and adaptation in the LEGO and ROBBO environment among students and teachers, which is explained by the intuitive understanding of the resources and the set of these projects. In addition, organizing clubs and courses in robotics can bring teachers closer to students, which will create a favorable atmosphere and friendly relations for further learning (Table 1). 
Table 1. Comparative characteristics of resources LEGO and "ROBBO".

\begin{tabular}{|c|c|c|c|}
\hline LEGO & Assignment & ROBBO & Assignment \\
\hline $\begin{array}{l}\text { LEGO } \\
\text { Technic }\end{array}$ & $\begin{array}{l}\text { The assembly technique has } \\
\text { been worked out in great } \\
\text { detail, and the finished } \\
\text { structure is actually a } \\
\text { miniature copy of the } \\
\text { original. It includes } \\
\text { mechanical and pneumatic } \\
\text { parts, an inertial motor, due } \\
\text { to which the assembled } \\
\text { model moves. The series } \\
\text { includes almost all types of } \\
\text { transport. }\end{array}$ & $\begin{array}{l}\text { Educational module } \\
\text { for the preparation } \\
\text { and conduct of } \\
\text { World Skills Junior } \\
\text { competitions. }\end{array}$ & $\begin{array}{l}\text { Educational module for } \\
\text { the preparation and } \\
\text { conduct of World Skills } \\
\text { Junior competitions. }\end{array}$ \\
\hline Technic $^{\mathrm{TM}}$ & $\begin{array}{l}\text { Designed for experienced } \\
\text { LEGO constructors. With the } \\
\text { LEGO Technic TM series, } \\
\text { your child can build } \\
\text { complex, realistic } \\
\text { mechanisms such as a } \\
\text { gearbox, moving piston } \\
\text { engine, steering system, and } \\
\text { crane boom. }\end{array}$ & $\begin{array}{c}\text { Educational module } \\
\text { for advanced study } \\
\text { of mechanics. }\end{array}$ & $\begin{array}{l}\text { Educational module for } \\
\text { in-depth study of } \\
\text { mechanics, } \\
\text { mechatronics, } \\
\text { automated control } \\
\text { systems. }\end{array}$ \\
\hline $\begin{array}{l}\text { TETRIX } \\
\text { MAX Kit with } \\
\text { PRIZM }\end{array}$ & $\begin{array}{l}\text { Using this kit, students will } \\
\text { be able to create and program } \\
\text { autonomous robots } \\
\text { controlled by the PRIZM } \\
\text { controller. This controller is } \\
\text { Arduino-like, which allows } \\
\text { you to connect any } \\
\text { compatible sensors and } \\
\text { expansion modules to the } \\
\text { robot. The PRIZM controller } \\
\text { is programmed in the } \\
\text { professional text language C. }\end{array}$ & $\begin{array}{c}\text { Educational module } \\
\text { for advanced study } \\
\text { of mechanics, World } \\
\text { Skills. }\end{array}$ & $\begin{array}{l}\text { An educational kit for } \\
\text { advanced study of } \\
\text { mechanics, } \\
\text { mechatronics, } \\
\text { automated control } \\
\text { systems and } \\
\text { preparation for } \\
\text { participation in World } \\
\text { Skills competitions. }\end{array}$ \\
\hline $\begin{array}{l}\text { TETRIX } \\
\text { MAX Kit with } \\
\text { NI myRIO }\end{array}$ & $\begin{array}{l}\text { This kit will allow students to } \\
\text { create autonomous robots to } \\
\text { compete in the World Robot } \\
\text { Olympiad (WRO) } \\
\text { international competition. } \\
\text { The kit includes a high- } \\
\text { performance NI myRIO } \\
\text { controller and LabVIEW } \\
\text { software for solving your } \\
\text { most complex technical } \\
\text { problems. }\end{array}$ & $\begin{array}{c}\text { Educational module } \\
\text { for advanced study } \\
\text { of robotics. }\end{array}$ & $\begin{array}{l}\text { A class kit for } \\
\text { advanced study of } \\
\text { robotics on topics: } \\
\text { preparation for a } \\
\text { robotics competition. }\end{array}$ \\
\hline $\begin{array}{l}\text { TETRIX } \\
\text { PRIME with } \\
\text { remote control }\end{array}$ & $\begin{array}{c}\text { The TETRIX Resource Kit } \\
\text { includes } 40 \text { metal building } \\
\text { elements, thus expanding the } \\
\text { element base of the TETRIX } \\
\text { Core Kit. } \\
\text { This kit is used to build more } \\
\text { complex robotics projects } \\
\text { and to prepare for FTC } \\
\text { competitions. }\end{array}$ & $\begin{array}{l}\text { Educational module } \\
\text { for learning the } \\
\text { basics of robotics. }\end{array}$ & $\begin{array}{l}\text { A set for a class for } \\
\text { studying the basics of } \\
\text { robotics on the topics - } \\
\text { design, electronics and } \\
\text { microprocessors, } \\
\text { information systems } \\
\text { and devices. }\end{array}$ \\
\hline
\end{tabular}




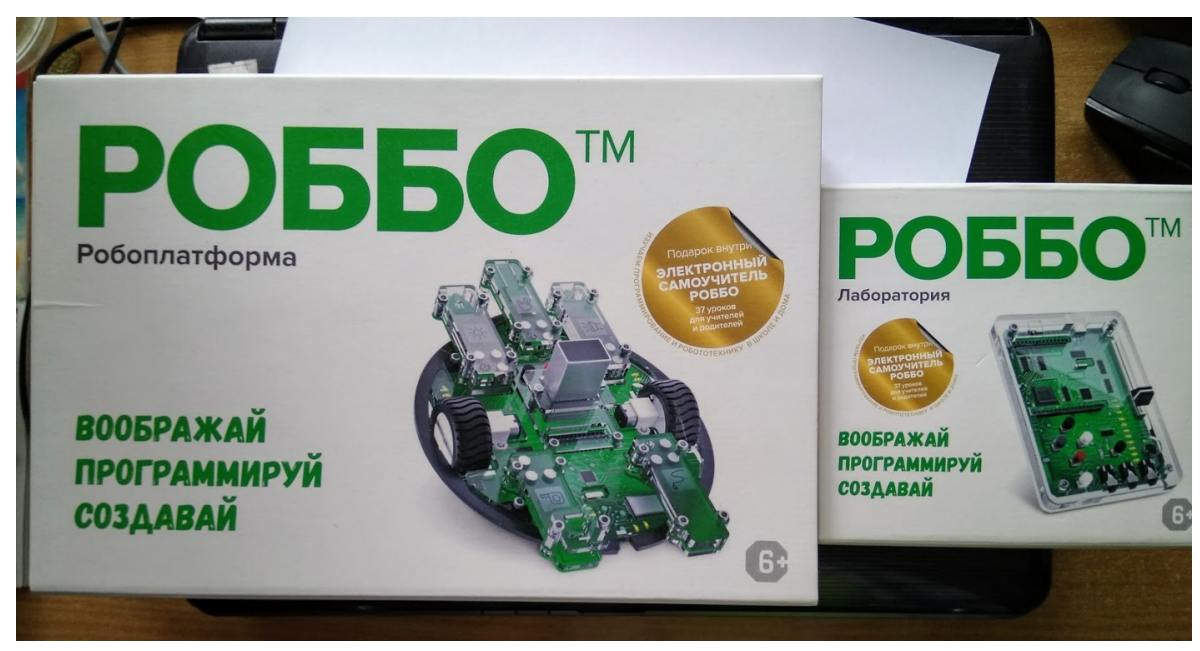

Fig. 1. Set of Robot Platform.

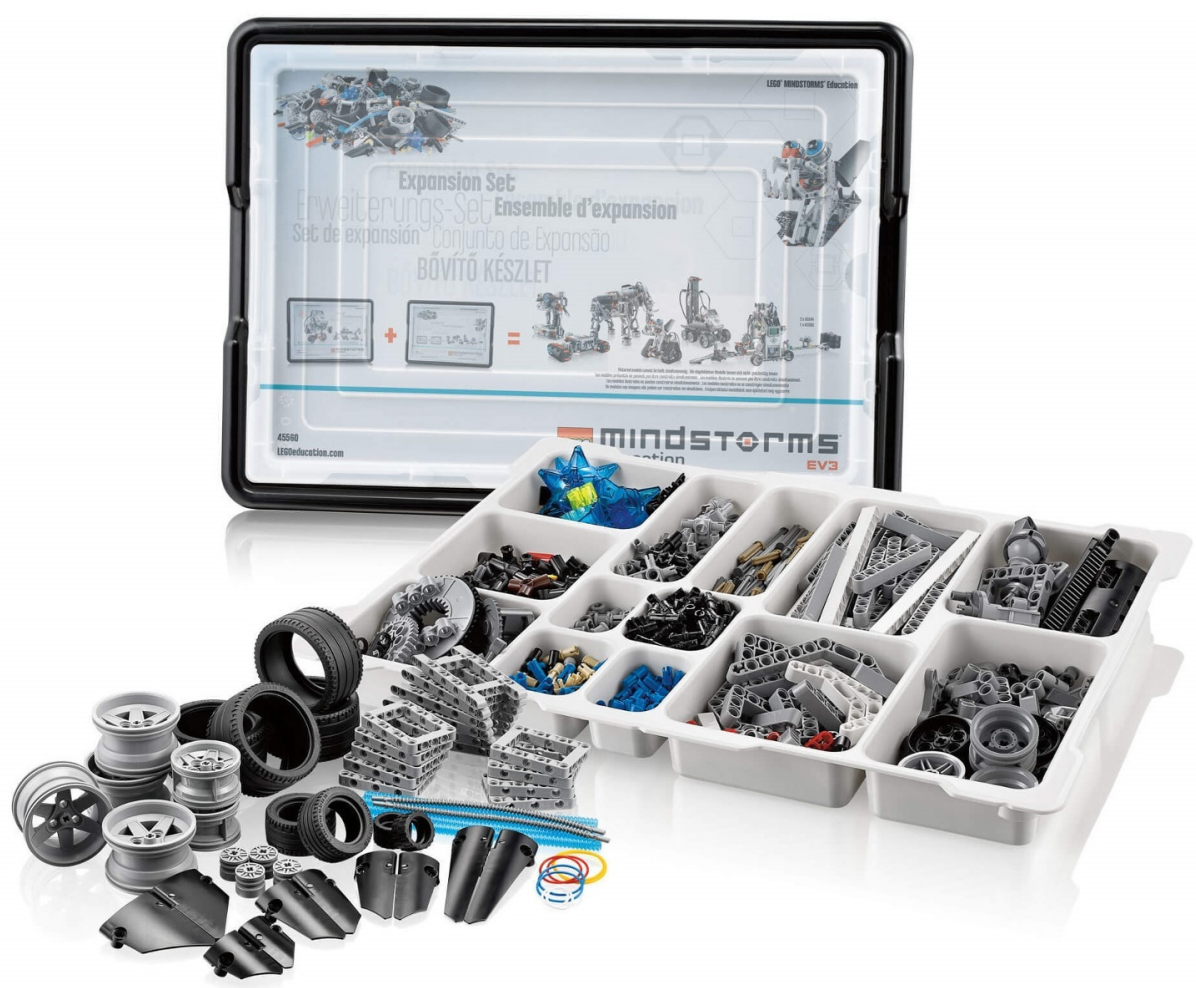

Fig. 2. Set of Robot Platform.

\section{Conclusion}

Thus, the following results are obtained. The use of educational software environments in programming lessons can radically change the student's idea of programming at school, develop spatial thinking in him and consolidate the material he has learned. The analysis of theoretical literature has shown that in the modern world and in schools, there is a need to 
introduce robotics into the extracurricular activities of students in secondary school as an element of additional education. This implementation will make the school competitive, and the assimilation of material by students in the classroom will be more effective, primarily due to the meta-subject connections of robotics with other school subjects. In the course of studying the LEGO and ROBBO constructors themselves, their software and capabilities, it was revealed that when designing, the priority area of the student's creative abilities is the development of his technical and communication skills. Thanks to classes in robotics, the student will be able to better understand design and programming, which will have a beneficial effect on his career guidance. Programming is an area of order and structure, because without these components, no program will work stably and correctly.

\section{References}

1. A.N. Bobrov, Young Scientist [Molodoy ychenyy], 24(104), 61-64 (2015)

2. O.G. Dieva, Pedagogy: traditions and innovations: materials of the III Int. Scientific Conf. $(85-87,2013)$

3. S.S. Kelbusova, Aspects and tendencies of pedagogical science: materials of the I Int. Scientific Conf. (St. Petersburg, Svoye Publishing House, 198-201, 2016)

4. S.G. Kosaretsky, B.V. Kupriyanov, D.S. Filippova, Education Issues, 1, 168-190 (2016)

5. E.A. Kuznetsova, Pedagogical skills: materials of the X Int. Scientific Conf. (Moscow, Buki-Vedi, 75-77, 2017)

6. R.V. Naumov, Actual programming languages, URL: https://cyberleninka.ru/article/n/aktualnye-yazyki-programmirovaniya (access date: 21.06.2020)

7. ROBBO, Free Educational Robotics (2013) URL: https://vk.com/scratchduino (access date: 14.03 .2020$)$

8. ROBBO project, Lessons in robotics. Everything you need to know, URL: http://robbo.ru/уроки-робототехники-все-что-нужно-зна/ (access date: 27.09.2019)

9. I.V. Shadrin, A tutorial on programming in the Lego Mindstorms EV3 environment (Kolpashevo, 40, 2017)

10. V.M. Kotov, A.I. Lapo, E.N. Voitekhovich, Pascal programming language, Electronic supplement to the textbook (2017) URL: http://informatika7.adu.by/?page_id=185 (access date: 11.05.2020)

11. T.P. Gegelashvili, Methodological guide for teachers of informatics of secondary school "Accelerated teaching of Basic language to 7-11 grades" (Leading educational portal of Russia "Infourok", 3, 2015)

12. T.V. Gorbunova, E.A. Leonova, Pedagogical technologies in teaching students - future teachers of informatics programming in the Scratch environment (Scientific electronic library "CyberLeninka", 1-2, 2019)

13. A. Chernyshov, What is programming and why is it needed (2014) URL: http://easyinformatics.ru/paskal-pascal/chto-takoe-programmirovanie-i-zachem-ononuzhno (access date: 16.05.2020)

14. S.P. Pineshkin, L.A. Chugunova, Modern programming languages in the course of computer science and ICT (Scientific electronic library "CyberLeninka", 2-3, 2011)

15. Why schoolchildren do not like programming lessons, Yandex Workshop "CODE" Journal URL: https://thecode.media/mariya-ivanovna (access date: 21.05.2020) 